\section{Revistade \\ Economid \\ Contemporâned}

\title{
IMPACTOS DOS PREÇOS DA GASOLINA E DO ETANOL SOBRE A DEMANDA DE ETANOL NO BRASIL
}

\author{
André de Souza Melo \\ Yony de Sá Barreto Sampaio ${ }^{b}$ \\ aprofessor do Programa de Pós-Graduação em Administração e Desenvolvimento Rural da Universidade \\ Federal Rural de Pernambuco (UFRPE). \\ 'Professor do Programa de Pós-Graduação em Economia na UFPE.
}

Artigo recebido em 21/06/2013 e aprovado em 14/07/2014.

RESUMO: Este trabalho analisa a relação entre o mercado de gasolina e o de etanol. A literatura relaciona apenas o efeito substituição entre os combustíveis. No entanto, o Brasil, além de possuir um substituto direto da gasolina (o etanol), possui o etanol misturado na gasolina, de forma que pode existir um efeito complementaridade. Dessa forma, por meio do modelo de Vetores Autorregressivos Estruturais, procurou-se entender esses dois efeitos. Com relação aos resultados, nota-se no curto prazo que o efeito do preço da gasolina é maior na demanda de etanol. Em longo prazo, porém, os consumidores aumentam a demanda pelo biocombustível. Além disso, a entrada dos veículos flex no Brasil não ocasionou um aumento na demanda e no preço do etanol, porém, a crise afetou positivamente o preço do biocombustível. Como implicação, nota-se que a escolha do consumidor pela gasolina é predominante no curto prazo. No entanto, um aumento repentino no preço do combustível fóssil leva a uma substituição de combustíveis no prazo. Deve-se, assim, garantir o

Correspondência para André de Souza Melo.

E-mail: andredesouzam@gmail.com. 
abastecimento de etanol no mercado doméstico para não afetar o consumidor com o aumento dos dois combustíveis no longo prazo.

PALAVRAS-CHAVE: Gasolina; etanol; efeito substituição; efeito complementaridade; vetores autorregressivos estruturais.

CLASSIFICAÇÃO JEL: L71; Q16; D12.

\title{
IMPACTS OF GASOLINE AND ETHANOL PRICES ON BRAZILIAN ETHANOL DEMAND
}

\begin{abstract}
This paper analyzes the relationship between gasoline and ethanol markets. Previous researches emphasize on substitution effect between gasoline and ethanol. However, in Brazil gasoline and ethanol are substitutes and complementary goods. We investigate the substitution and complementarity effects between fuels by using Structural Vector Autoregressions Vector (SVAR). As a result, in the short run gasoline price shock effect in ethanol demand is greater than ethanol price shock. In the long run, however, consumers make the consumption of ethanol grow. Furthermore, the introduction of flex fuel technology in Brazil did not produce any impact on ethanol price and demand. The crisis has affected positively the biofuel price nevertheless. As an implication, due to gasoline price shock the sucroalcohol sector must guarantee the ethanol domestic supply in the long run.
\end{abstract}

KEYWORDS: Gasoline; ethanol; substitution effect; complementarity effect; SVAR. 


\section{INTRODUÇÃO}

O mercado de gasolina no Brasil mostra-se relacionado com o do etanol. Desde a década de 1970, com o primeiro choque do petróleo, por meio do Proálcool, houve o estímulo à produção de etanol com o intuito de substituir a gasolina, com a fabricação de veículos abastecidos a etanol - o chamado etanol hidratado. Além disso, a gasolina consumida pelos usuários de veículos abastecidos pelo combustível fóssil era misturada com etanol - chamado de etanol anidro -, com o objetivo de não apenas estabilizar o preço doméstico da gasolina, mas também reduzir as emissões poluentes.

Dessa forma, até 2003, a elasticidade de substituição entre a demanda de etanol e o preço da gasolina era muito baixa, pois para o consumidor trocar de combustível era necessário trocar de veículo para consumir o combustível mais barato (Tokgoz e Elobeid, 2006). No entanto, a partir de maio de 2003, foi implantada uma nova tecnologia nos veículos que permitiu ao consumidor abastecer o veículo com qualquer mistura entre o etanol hidratado e a gasolina. Os veículos dotados dessa tecnologia são chamados de flex fuel. Isso permitiu ao consumidor optar pelo combustível mais barato.

Além dos veículos flex, o aumento do preço do petróleo e as questões ambientais relativas às emissões de poluentes de fato estimularam a produção de etanol no Brasil e no mundo. Como o Brasil vivenciou o sucesso do Proálcool, foi adquirida vantagem competitiva na produção do etanol oriundo da cana-de-açúcar, o que permite ao etanol competir com a gasolina mesmo com o preço do petróleo em baixa (Von Lampe, 2006). Com isso, o país figura como o segundo maior produtor mundial de etanol e o primeiro em etanol de cana-de-açúcar.

Tabela 1 - Produção mundial de etanol, 2012 (em milhões de galões)

\begin{tabular}{lc}
\hline \multicolumn{1}{c}{ País/Região } & Produção \\
\hline Estados Unidos & 13317,90 \\
Brasil & 5557,9 \\
Canadá & 449 \\
Ásia & 952 \\
Austrália & 71 \\
União Europeia & 1139,52 \\
Total & 21487,32 \\
\hline Fonte: RFA Outlook 2013
\end{tabular}

Fonte: RFA Outlook 2013

Como pode ser visto na Tabela 1, o Brasil perde apenas para os Estados Unidos na produção de etanol no mundo, com pouco mais de cinco bilhões de galões, contra 13 bilhões de galões, respectivamente. Apesar de apontar o estímulo do uso de biocombustível em decorrência da alta do preço do barril de petróleo e fatores climáticos, a 
introdução dos veículos flex foi um meio de sucesso para a recuperação do mercado produtor de etanol (Giesecke et al., 2007).

A revisão de literatura mostra que existe uma gama de trabalhos que analisam esse efeito de substituição entre o etanol e a gasolina, como, por exemplo, os de Boff (2010), Tokgoz e Elobeid (2006), Iootty et al. (2009). No entanto, essa inter-relação entre os mercados de etanol e gasolina no Brasil possui uma particularidade quando comparada com os outros países, em que o etanol e a gasolina são bens complementares, já que o consumidor adquire o combustível com o etanol anidro misturado com a gasolina. No Brasil, de acordo com Balcombe e Rapsomanikis (2008), a nova composição da frota fez surgir uma complexa relação entre os combustíveis gasolina e etanol, sendo eles complementares e substitutos um do outro. Segundo os autores, para consumidores com veículos movidos exclusivamente pela mistura etanol anidro e gasolina, um aumento no preço da gasolina resulta em uma queda na quantidade de etanol anidro demandado, que é consumido em conjunto com a gasolina. Para os consumidores com veículos flex, um aumento no preço da gasolina resulta em uma mudança na curva de demanda de etanol mais elástica para a direita. Então o preço da gasolina influencia a demanda de etanol anidro e a demanda por etanol hidratado.

No entanto, o consumidor de veículos flex não enxerga como referência, na troca entre os combustíveis, o preço da gasolina e do etanol isoladamente, mas sim o preço relativo entre os dois combustíveis. Esse comportamento é justificado, pois o rendimento do carro abastecido por etanol hidratado é 30\% menor do que o do veículo abastecido pela gasolina. Ou seja, se a relação entre o preço do álcool e o da gasolina for maior que 0,7 , o consumidor escolhe abastecer o carro com gasolina e, se a relação de preços for menor que 0,7 , o consumidor encolhe abastecê-lo com etanol (Losekann e Castro, 2011).

A expansão da demanda de etanol e a vantagem de o consumidor abastecer com etanol em detrimento da gasolina era um fator atrativo ao produtor de etanol ${ }^{1}$. No entanto, a escassez de investimentos no setor sucroalcooleiro decorrente da crise de 2009 e o alto preço do açúcar ${ }^{2}$ no mercado internacional acarretaram uma queda na produção de etanol para abastecer o mercado doméstico (Viegas, 2011). A demanda continuou crescendo, e os preços do etanol hidratado subiram. De acordo com Viegas

\footnotetext{
1 Abastecer com etanol era mais atrativo para o consumidor com relação à gasolina. Segundo a ANP (2012), a relação de preços dos combustíveis preponderante após introdução dos veículos flex era menor que 0,7 .

2 O açúcar é oriundo da mesma matéria-prima do etanol. O aumento do preço internacional do açúcar é um fator de atração do produtor para o aumento da produção do açúcar em detrimento do etanol (Goldemberg et al., 2004b).
} 
(2011), a competitividade do etanol foi reduzida gradativamente após a crise, e ele perdeu mais espaço para a gasolina, ficando mais caro que o etanol norte-americano. Com isso, o Brasil aumentou as importações de etanol dos Estados Unidos, já que não conseguia ofertar o suficiente para suprir a demanda interna, perdendo, assim, a oportunidade de alavancar o mercado mundial de etanol.

Sabendo disso, a intenção deste artigo é estudar os impactos no consumo de etanol anidro e hidratado em face de um choque no preço da gasolina em relação ao do etanol, de forma a compreender com mais clareza essa complexa relação entre os combustíveis comercializados no país.Este artigo está estruturado em seis seções além desta introdução. O segundo item investiga a literatura nacional e a internacional sobre a relação entre os mercados de etanol e gasolina. $\mathrm{O}$ terceiro discute um modelo teórico que engloba as variáveis de interesse no modelo empírico. O quarto item analisa a relação entre o mercado de gasolina e o de etanol através de dados. O quinto item tece comentários sobre a metodologia, e o sexto discute os resultados e as implicações. O sétimo e último item consiste numa conclusão sobre o tema.

\section{REVISÃO DE LITERATURA}

A análise da literatura aponta uma relação entre os mercados de gasolina e etanol, como se pode conferir em Boff (2010), Tokgoz e Elobeid (2006), Iootty et al. (2009) e Badr et al. (2008).

$\mathrm{Na}$ literatura internacional destaca-se o trabalho de Tokgoz e Elobeid (2006), cujo resultado mostra que a composição da frota de veículos (o fato de ser bicombustível ou não) determina o consumo do etanol e o preço da gasolina no Brasil. Foi encontrada no estudo a informação de que mudanças nos custos dos insumos afetam a rentabilidade dos produtores de etanol e o preço doméstico do biocombustível. Ainda na literatura internacional, Giesecke et al. (2007) afirmam que o crescimento da demanda mundial pelo etanol brasileiro parece ser menos importante para a expansão do etanol do que o mercado interno, pois, segundo eles, o crescimento das exportações do etanol brasileiro é menor do que o crescimento da demanda interna. Os autores destacam a importância dos veículos flex para a retomada do mercado de etanol no Brasil e concluem que o crescimento doméstico da demanda - via aumento da produção de veículos flex - é acompanhado por um rápido crescimento nos setores de produção de etanol, o que caracteriza, assim, uma resposta rápida da oferta de etanol, que faz com que seu preço diminua.

Outros trabalhos também relatam que a introdução dos veículos flex foi determinante para o aumento da produção de etanol hidratado para o abastecimento do- 
méstico (Boff, 2010; Balcombe e Rapsomanikis, 2008; Du e Carriquiry, 2011). De acordo com Boff (2010), por exemplo, a entrada dessa nova tecnologia causou uma mudança na relação entre a demanda de combustíveis etanol e gasolina, e , no longo prazo, a elasticidade da transmissão de preço estimada do etanol com respeito à gasolina (açúcar) aumenta no tempo em direção a um (diminui com o tempo em direção a zero).

Ferreira et al. (2009) encontraram que os preços dos combustíveis dependerão das proporções de álcool, gasolina e carros flex no estoque total. A demanda por determinado tipo de combustível dependerá do preço esperado do álcool e da gasolina. No longo prazo, foi encontrada uma forte causalidade entre os preços da gasolina e do etanol. Losekann e Castro (2011) afirmam, por sua vez, que o preço relativo dos combustíveis é o critério preponderante de escolha do consumidor.

$\mathrm{Na}$ investigação a respeito do grau de substituição da gasolina por etanol, observou-se na literatura que Roppa (2005) e Alves e Bueno (2003) não encontraram resultados significativos sobre a relação entre preço de etanol e consumo de gasolina. Azevedo (2007) realizou o mesmo exercício, porém, relaciona o etanol com outros combustíveis para o Brasil e suas regiões. Entre os resultados encontrados, destaca-se que etanol e gasolina são substitutos de curto prazo, embora o crescimento do consumo de etanol mostre-se superior ao consumo de gasolina na magnitude de 1,03 ao longo do período estudado (dados mensais de 2002 a 2006). Entretanto, Iooty et al. (2009) encontraram um alto grau de substituição entre gasolina e etanol, maior do que entre a gasolina e o GNV.

No tocante ao consumo conjunto de etanol e gasolina, Bailis et al. (2011), Vendenov et al. (2005) e Boff (2010) mostram que a mistura do etanol na gasolina reduz a volatilidade no preço do combustível fóssil. No entanto, eles não atentaram para a relação entre o preço da gasolina e a demanda de etanol anidro (efeito complementaridade). Tokgoz e Elobeid (2006), por sua vez, destacam o efeito substituição e complementaridade. Segundo eles, com o preço do petróleo em altos patamares, o número de veículos bicombustíveis crescerá significativamente, e isso ocasionará um crescimento da demanda por etanol hidratado. No estudo dos autores, um choque no preço da gasolina na ordem de $20 \%$ ocasiona uma queda na demanda por esse produto e na demanda por álcool anidro em 5,2\%. Entretanto, o consumo de etanol hidratado crescerá 2,6\% devido ao efeito substituição da gasolina por etanol, permitido pela existência dos veículos flex.

Em suma, para o Brasil, os trabalhos que abordam esse assunto restringem-se apenas à análise do efeito substituição da gasolina e etanol por meio da estimação da demanda de combustíveis. Existe, portanto, escassa literatura que aponta a presença dos efeitos substituição e complementaridade entre os combustíveis. 


\section{MODELO TEÓRICO}

Assume-se primeiramente que o consumidor é tomador de preço, ou seja, o indivíduo observa o preço e escolhe qual combustível é mais adequado. Como no presente artigo pretende-se analisar a substituição e a complementaridade entre os combustíveis, as variáveis de interesse serão a demanda de etanol anidro e hidratado, o preço da gasolina e o preço do etanol na bomba, a frota de veículos flex e a imposição da mistura de etanol anidro na gasolina.

De acordo com Tokgoz e Elobeid (2006), a frota brasileira antes de 2003 era composta principalmente por veículos abastecidos por etanol ou gasolina. Quando havia mudanças no preço da gasolina, apenas os consumidores de gasolina eram afetados, enquanto que os consumidores com veículos abastecidos por etanol não o eram. Com a introdução dos veículos flex, os consumidores que utilizam essa tecnologia se mostram mais sensíveis à mudança no preço da gasolina. Um aumento nesse preço resulta em um declínio mais acentuado na demanda por gasolina, de forma que se pode diminuir o consumo de etanol anidro e aumentar o consumo de etanol hidratado. A demanda de etanol hidratado é deslocada para a direita, aumentando, assim, o preço desse biocombustível (Balcombe e Rapsomanikis, 2008). Com o aumento do número de veículos flex no Brasil, a sensibilidade do consumidor aos preços do etanol e da gasolina torna-se mais acentuada.

\subsection{MODELO PARA O ETANOL BRASILEIRO}

A demanda brasileira de etanol é dividida entre a demanda de etanol anidro e hidratado. Assume-se que as demandas respondem diferentemente a incentivos econômicos dependendo de três tipos de veículos (álcool, flex e gasolina). A equação comportamental para o consumo de etanol anidro inclui, além do preço do etanol anidro, a imposição da mistura de $20 \%$ a $25 \%$, pois o etanol anidro é utilizado somente como mistura em nível de imposição. A equação para o etanol hidratado inclui o número de veículos flex na frota de veículos, já que o etanol hidratado é utilizado nesses veículos em qualquer nível. O preço da gasolina é fator determinante das duas demandas, como já explicado. Para as duas equações também inclui-se um termo de interação entre a razão da frota.

Com base no modelo de equilíbrio parcial de Tokgoz e Elobeid (2006), os modelos de demanda por etanol anidro $\left(\mathrm{D}^{\mathrm{EA}}\right)$ e etanol hidratado $\left(\mathrm{D}^{\mathrm{EH}}\right)$ são tratados separadamente, ou seja, a demanda total de etanol no Brasil é $\mathrm{D}^{\mathrm{ET}}=\mathrm{D}^{\mathrm{EA}}+\mathrm{D}^{\mathrm{EH}}$. As equações de comportamento serão, pois: 


$$
\begin{aligned}
& D^{E A}=f\left(P^{E T}, P^{G A S}, \text { Interação, Mist, PIB }\right) \\
& D^{E H}=f\left(P^{E T}, P^{G A S}, \text { Interação, Flex, PIB }\right)
\end{aligned}
$$

Nessas equações, $P^{E T}$ representa o preço do etanol hidratado no Brasil. Optou-se por não colocar o preço do etanol anidro, pois, além de ele estar integrado ao preço da gasolina, existe alta correlação com o preço do etanol hidratado, e o custo de desidratação é constante (Tokgoz e Elobeid, 2006). $P^{G A S}$ é o preço da gasolina, e Interação é um termo de interação que é igual ao preço da gasolina vezes a razão dos veículos flex na frota total dos veículos. Mist é a imposição do governo de adicionar de $20 \%$ a $25 \%$ de etanol à gasolina, dependendo das condições de mercado. Flex denota o número de veículos flex na frota de veículos em unidades. PIB é o Produto Interno Bruto medido em reais, que indica a atividade econômica.

Segundo Tokgoz e Elobeid (2006), esse termo de interação é usado para capturar a maior sensibilidade da demanda pelos veículos flex no preço da gasolina. Como o número de flex aumenta no período de projeção, a demanda por etanol anidro e hidratado torna-se mais sensível a mudanças no preço da gasolina. No caso da demanda de etanol anidro, com o aumento do preço da gasolina, a demanda por etanol decai, pois os consumidores que possuem veículos flex substituem a gasolina misturada com etanol anidro pelo etanol hidratado. Então, os coeficientes de $P^{G A S}$ e Interação na equação 1 são negativos. De outra forma, a demanda por etanol hidratado aumenta se o preço da gasolina aumentar, pois os consumidores de veículos flex preferem o uso de etanol hidratado relativamente ao anidro misturado com a gasolina. Assim, os coeficientes de $P^{G A S}$ e Interação são positivos.

Esse modelo teórico, baseado nos modelos de Tokgoz e Elobeid (2006) e Balcombe e Rapsomanikis (2008), serve como norte para indicar de que maneira as variáveis explanadas na revisão de literatura influenciam as demandas de etanol anidro e hidratado.

\section{A RELAÇÃo ENTRE O PREÇO DA GASOLINA E O MERCADO DE ETANOL NO BRASIL}

Analisa-se de forma descritiva cada fator que influencia as demandas de etanol anidro e hidratado. Com relação à demanda de etanol anidro, a Figura 1 mostra a relação entre a demanda do biocombustível com a variação do preço da gasolina e a imposição à mistura. Percebe-se na Figura 1 que a demanda de etanol anidro varia de acordo com a variação no percentual da imposição da mistura. No início dos anos 2003 e 2006, por exemplo, mesmo com o aumento no preço da gasolina, a imposição reduziu-se para $20 \%$. Isso ocorre em virtude de o etanol estar em entressafra naquele período. A demanda de etanol anidro variou positivamente em decorrência de aumentos na imposição da mistura até março de 2006, quando se deu o crescimento da demanda de 
etanol hidratado. A partir dessa data, mesmo com a mistura predominantemente permanecendo em 25\%, a demanda de etanol anidro acompanhou a variação decrescente do preço da gasolina. Mesmo com tendência de alta na demanda de etanol anidro, observaram-se variações decrescentes do preço da gasolina. Com a crise, percebeu-se uma queda na imposição da mistura; no entanto, a demanda de anidro continuou a crescer e o preço da gasolina, a decrescer. Esse comportamento sugere que a variação da demanda de etanol anidro responde a mudanças na imposição da mistura, bem como ao preço da gasolina e à demanda de etanol.

Figura 1 - Comportamento do preço da gasolina e do etanol anidro*

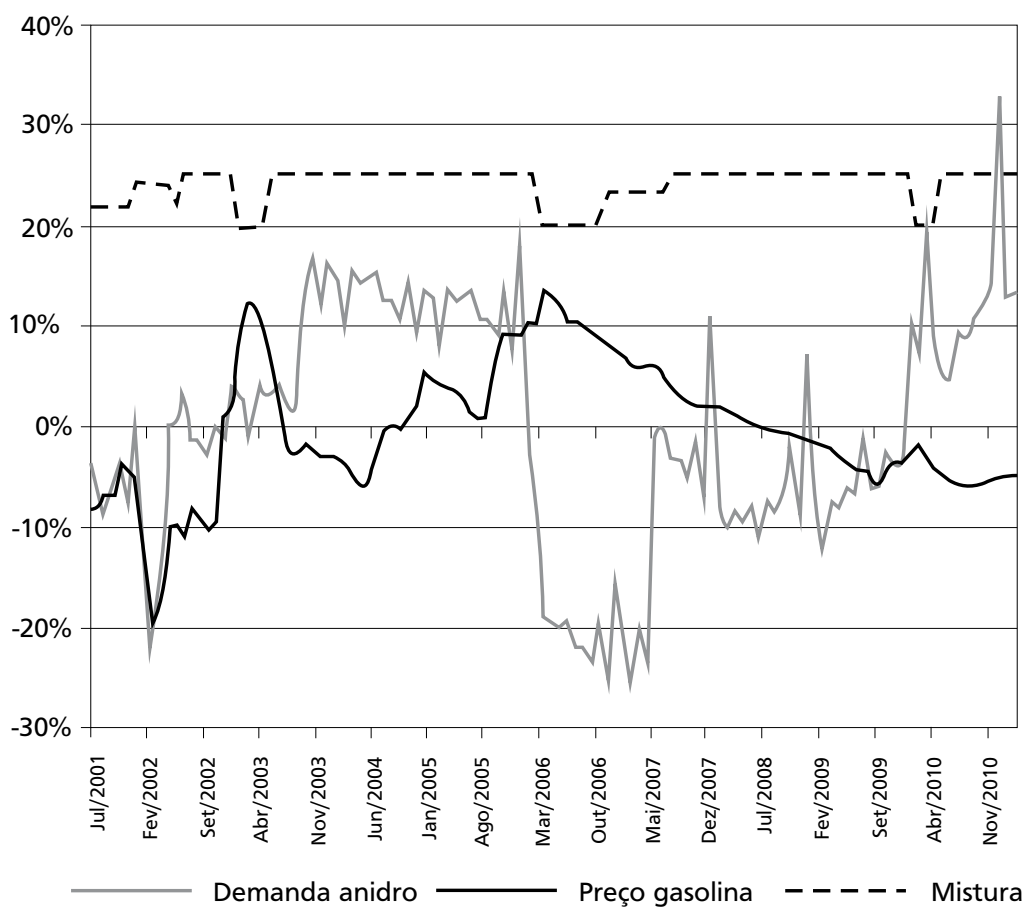

Nota: (*) As variáveis representam uma variação relativa à média de longo prazo. Fonte: Elaboração própria com base em dados da Datagro (2011) e ANP (2012).

A Figura 2 mostra a relação entre os preços de etanol e gasolina. Nota-se que os preços têm comportamentos semelhantes; entretanto, a volatilidade do preço do etanol é maior com relação ao preço da gasolina. Esse resultado indica que o preço da gasolina tende a ser mais controlado do que o preço do etanol hidratado, que não sofre nenhuma intervenção do governo desde 1998. As variáveis são apresentadas como variação em torno da média de longo prazo. 
Com relação à demanda de etanol anidro e hidratado, pode-se observar na Figura 3 que a razão entre os preços de etanol e gasolina ultrapassou $70 \%$ apenas cinco vezes. Ou seja, no período de análise, a vantagem de colocar gasolina aconteceu apenas em cinco momentos. No entanto, a partir de janeiro de 2011 predominou apenas a vantagem de abastecer com gasolina. Nota-se também que quando a razão de preços foi menor que $70 \%$ observou-se um crescimento da demanda de etanol hidratado e uma estabilidade na demanda de etanol anidro. Em março de 2010, quando era mais vantajoso abastecer com gasolina, a demanda de etanol hidratado caiu em decorrência do aumento do preço do etanol; e a demanda de etanol anidro aumentou. Esse fenômeno coincide com a crise de 2009, quando o setor sucroalcooleiro não conseguiu suprir a crescente demanda de etanol. Outra observação importante é que a incorporação dos veículos flex na frota brasileira em 2003 parece não ter influenciado a demanda de etanol, pois, após 2003 (Figura 4), a produção de etanol foi maior do que a demanda. Assim, com a entrada dessa nova tecnologia, a oferta teve um crescimento maior do que a demanda, o que pode não ocasionar um aumento no preço do produto.

Figura 2 - Preço da gasolina versus preço do etanol

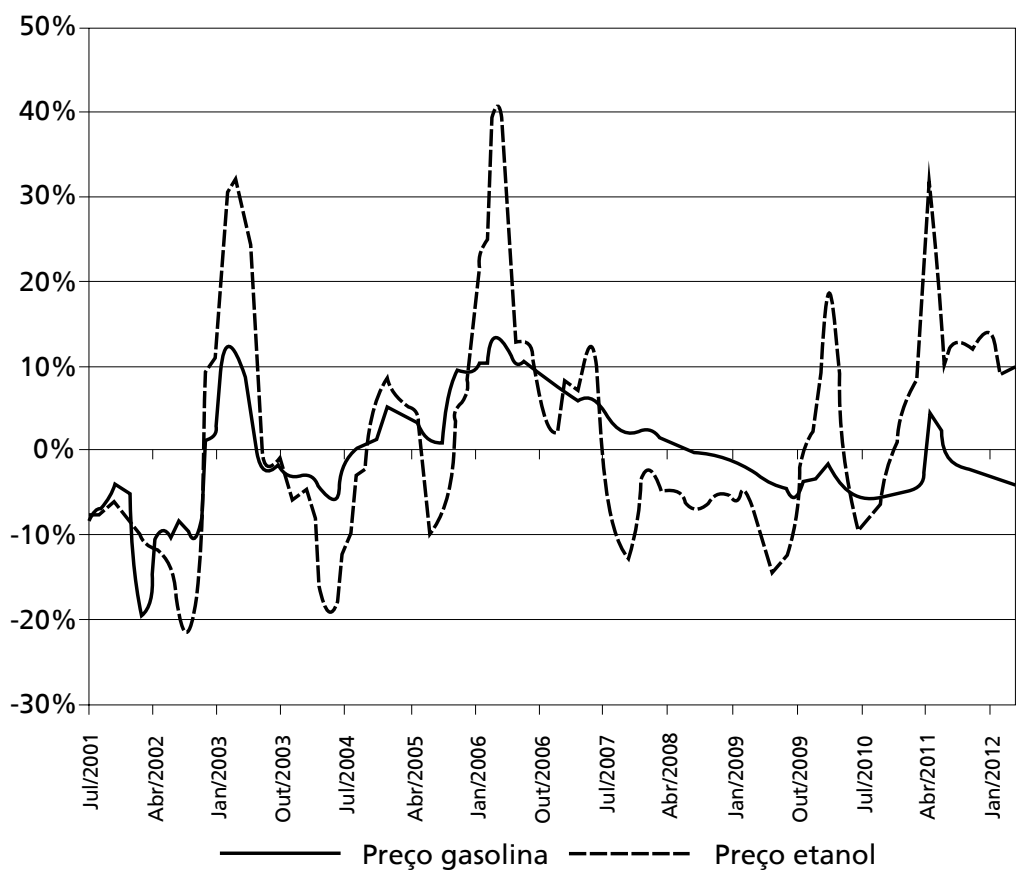

Fonte: Elaboração própria com base em em dados da ANP (2012). 
Figura 3 - Relação entre a demanda por etanol anidro, hidratado* e a razão de preços de etanol/gasolina

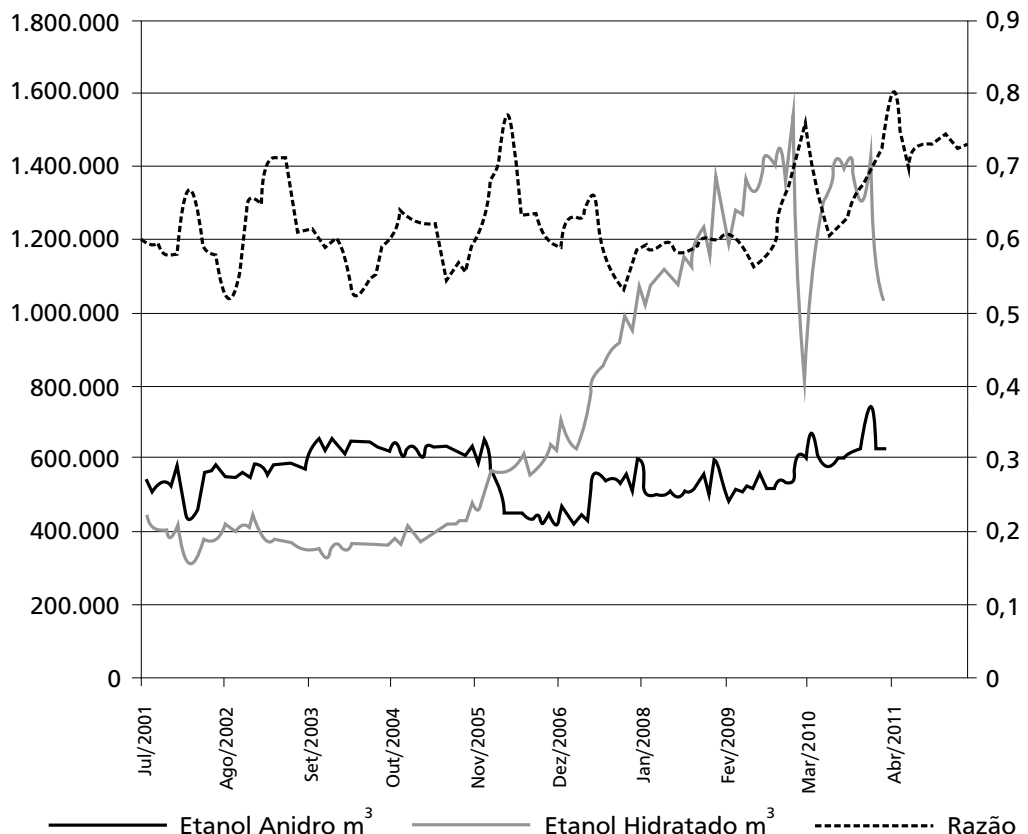

Nota: (*) Dados não disponibilizados a partir de abril de 2011

Fonte: Elaboração própria com base em dados da ANP (2012) e Datagro (2011).

Figura 4 - Evolução da demanda e oferta de etanol no Brasil

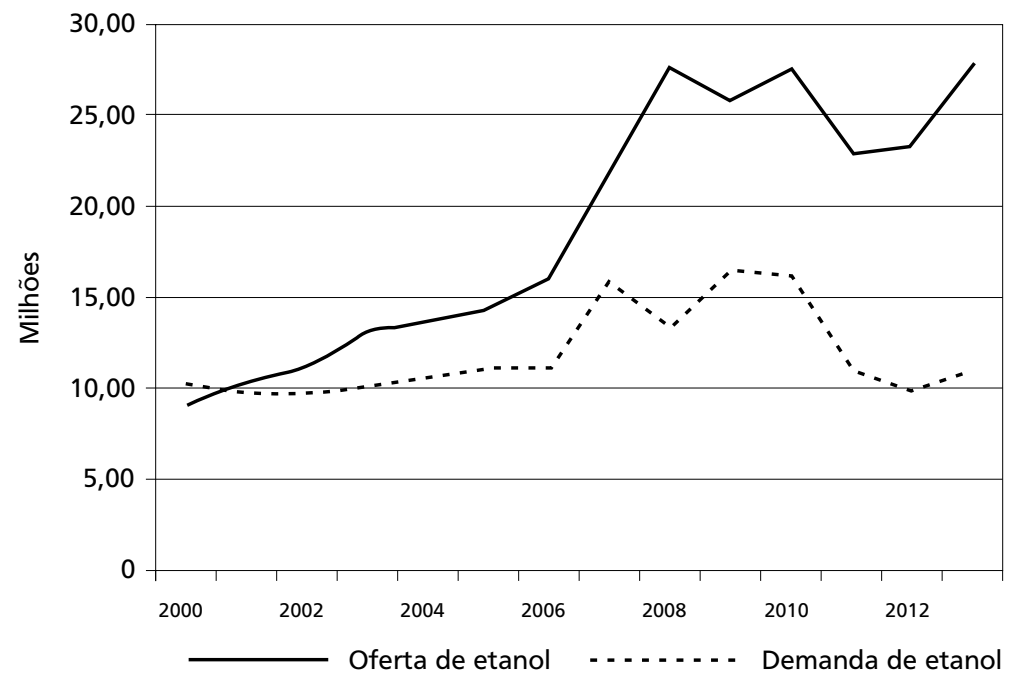

Fonte: UNICA (2014). 
Dada a análise descritiva dos dados, a partir deste momento torna-se necessário estimar um modelo conjunto de todas essas variáveis.

\section{MODELO EMPÍRICO}

A intenção deste estudo é analisar a presença do efeito de substituição e complementaridade entre os mercados de gasolina e etanol no Brasil. No entanto, observou-se na literatura que a maioria dos trabalhos no Brasil foca apenas o efeito de substituição entre os combustíveis, com esse efeito sendo analisado por meio da equação de demanda de gasolina, com o uso de séries temporais e mecanismo de correção de erro.

Vilela (2010) realiza um estudo exploratório sobre os modelos econométricos que analisam a demanda de combustíveis, e, nesses estudos, as variáveis dependentes são o consumo da gasolina ou o consumo de etanol, que têm como variáveis explicativas o preço da gasolina, o preço do etanol e a renda. Os modelos empíricos utilizados centram-se basicamente em modelos de séries temporais de cointegração e correção de erro (por exemplo, Burnquist e Bacchi, 2002; Alves e Bueno, 2003; Nappo, 2007; Schüneman, 2007; e Gomez, 2010).

Vale destacar os trabalhos de Tokgoz e Elobeid (2006) e Bailis et al. (2011), que analisam também o efeito complementar entre os combustíveis. O primeiro utiliza modelo estrutural de equilíbrio parcial e o segundo, modelo de volatilidade ARCH-M e GARCH-M. Neste trabalho propõe-se utilizar também a metodologia de vetores autorregressivos estrutural (SVAR), que está descrita no Apêndice do presente artigo.

Diferentemente do modelo teórico apresentado anteriormente, o modelo de vetores autorregressivos propõe que todas as variáveis descritas no modelo teórico sejam endógenas. As variáveis utilizadas serão: consumo de etanol anidro (que é misturado com a gasolina), consumo de etanol hidratado, preço da gasolina e preço do etanol. As demandas serão afetadas por choques no preço da gasolina e do etanol. As respostas mostrarão uma preferência pelo biocombústivel ou por gasolina.

No modelo é analisada também a decomposição da variância, que mostra o quanto da variação da demanda de etanol hidratado e anidro advém de mudanças no preço da gasolina e etanol. Assim, o modelo empírico será estimado através dos vetores autorregressivos estruturais com as seguintes variáveis endógenas:

$$
y_{t}=\text { prodind }, P_{t}^{G A S}, P_{t}^{E T}, D_{t}^{E A}, D_{t}^{E H}
$$

Na equação, $P_{t}^{G A S}$ é o preço médio da gasolina na bomba ao longo do tempo; $P_{t}^{E T}$ é o preço médio do etanol hidratado ao longo do tempo; $D_{t}^{E A}$ representa a demanda por 
etanol anidro; $D_{t}^{E H}$ representa a demanda de etanol hidratado ao longo do tempo e prodind $_{t}$ é o produto industrial que representa o nível de atividade da economia brasileira, esta última sendo considerada uma variável de controle.

De acordo com trabalhos revisados e através de investigação empírica, o processo de identificação ocorre de forma recursiva, onde a variável de preço da gasolina afeta de forma contemporânea todas as variáveis, mas não é afetada por nenhuma delas. Em seguida, o preço de etanol afeta de forma contemporânea as demandas de etanol anidro e hidratado e assim por diante.

Então, o modelo a ser estimado, de acordo com a identificação de forma recursiva de Cholesky, é descrito como:

$$
\left[\begin{array}{ccccc}
1 & 0 & 0 & 0 & 0 \\
a_{21} & 1 & 0 & 0 & 0 \\
a_{31} & a_{32} & 1 & 0 & 0 \\
a_{41} & a_{42} & a_{43} & 1 & 0 \\
a_{51} & a_{52} & a_{53} & a_{54} & 1
\end{array}\right]\left[\begin{array}{l}
\text { prodind }_{t} \\
P_{t}^{G A S} \\
P_{t}^{E T} \\
D_{t}^{E A} \\
D_{t}^{E H}
\end{array}\right]=[F] \cdot\left[\begin{array}{l}
\text { prodind }_{t-1} \\
P_{t-1}^{G A S} \\
P_{t-1}^{E T} \\
D_{t-1}^{E A} \\
D_{t-1}^{E H}
\end{array}\right]+\mathrm{C} \xi
$$

Das equações (1) e (2) descritas anteriormente, as variáveis de Interação e Flex que dependem da frota de veículos flex não estão disponíveis para o período de análise. Para resolver esse problema coloca-se uma variável dummy temporal que represente a introdução dos veículos flex no Brasil em 2003. Com relação à variável MIST, uma dummy de intervenção inserida no modelo é a imposição da mistura de $20 \%$ a $25 \%$ de etanol anidro na composição da gasolina. Outra variável de interesse seria a razão entre os preços de etanol e de gasolina, porém, na amostra analisada, a vantagem de colocar gasolina em relação ao etanol ocorreu poucas vezes. Então, não foi colocada essa variável no modelo. Por fim, analisa-se o efeito da crise de 2009, que gerou carência de investimentos no setor sucroalcooleiro, através de uma dummy temporal, que indica o período de crise internacional a partir de outubro de 2009.

Optou-se neste trabalho pela estimação do VAR nas variáveis em nível, pois as variáveis na primeira diferença eliminariam qualquer chance de detectar efeitos de persistência nos choques nas variáveis de interesse. De acordo com Kilian (2010), a vantagem de especificação no nível é que a estimação do VAR é consistente mesmo que as variáveis sejam integradas ou não. Além disso, inferências padrão nos impulsos respostas baseados em modelos $\operatorname{VAR}(\mathrm{p}), \mathrm{p}>1$, em nível, são assintoticamente válidas. De acordo com Sims, Stock e Watson (1990), inferência também é assintoticamente invariante para a possível presença de cointegração entre as séries. 
Os dados de demanda de etanol anidro e hidratado foram cedidos pela Datagro (2012) e os dados de preço de etanol e gasolina, pela Agência Nacional de Petróleo e Biocombustível (ANP), todos com periodicidade mensal de julho de 2001 até março de 2011. As variáveis foram colocadas em logaritmo para se visualizar as elasticidades com maior facilidade. A série de etanol anidro foi dessazonalizada pelo método multiplicativo.

\section{RESULTADOS}

\subsection{ESTIMAÇÃO DO MODELO ECONOMÉTRICO}

De acordo com o explanado na metodologia, o modelo será estimado por meio do método de vetores autorregressivos estrutural. Primeiramente, observa-se se as variáveis ao longo do tempo se distanciam da média. Ou seja, é necessário testar se cada variável é estacionária. De acordo com Enders (2001), quando mais de uma série possui raiz unitária, ou é não estacionária, é necessária a estimação de vetores de correção de erro para saber o comportamento das variáveis no longo prazo. No entanto, as variáveis estudadas no presente artigo são estacionárias, exceto a variável demanda de etanol hidratado.

Os testes realizados para presença de raiz unitária foram o Dickey Fuller Aumentado (ADF), o KPSS e o Phillip Perron. Este último é importante devido à presença de algumas quebras estruturais no comportamento das séries, que podem comprometer os resultados dos testes. A Tabela 3 mostra o resultado dos testes.

Tabela 3 - Teste de raiz unitária para as variáveis selecionadas

\begin{tabular}{lccccc}
\hline Variável & Teste ADF & Lags & Teste KPSS (5\%) & Teste de Perron & Resultado \\
\hline Preço da Gasolina & $-2,303(-3,41)$ & 2 & $0,437(0,146)$ & $-5,83(-5,08)$ & $\mathrm{I}(0)$ \\
Preço do Etanol & $-3,98(-3,41)$ & 1 & $0,153(0,146)$ & $-5,60(-5,08)$ & $\mathrm{I}(0)$ \\
Demanda de Etanol Anidro & $-2,29(-3,41)$ & 0 & $0,232(0,146)$ & $-5,09(-5,08)$ & $\mathrm{I}(0)$ \\
Demanda de Etanol Hidratado & $-2,23(-3,41)$ & 12 & $0,352(0,146)$ & $-3,34(-5,08)$ & $\mathrm{I}(1)$ \\
Produção Industrial & $-2,62(-3,41)$ & 0 & $0,177(0,146)$ & $-8,11(-5,08)$ & $\mathrm{I}(0)$ \\
\hline
\end{tabular}

Nota: Todas as séries são consideradas com tendência.

Fonte: Elaboração própria.

Uma vez determinada a presença de raiz unitária, é necessário determinar o número de defasagens do modelo. Para tal análise realizaram-se dois testes, o de Razão de Verossimilhança e o de Akaike para pequenas amostras. O número de defasagens sugerido pelos testes foi de dois lags. Para preservar a memória autorregressiva dos dados mensais, optou-se pelo modelo com maior defasagem. 
Figura 5 - Resposta de um choque de demanda de etanol hidratado
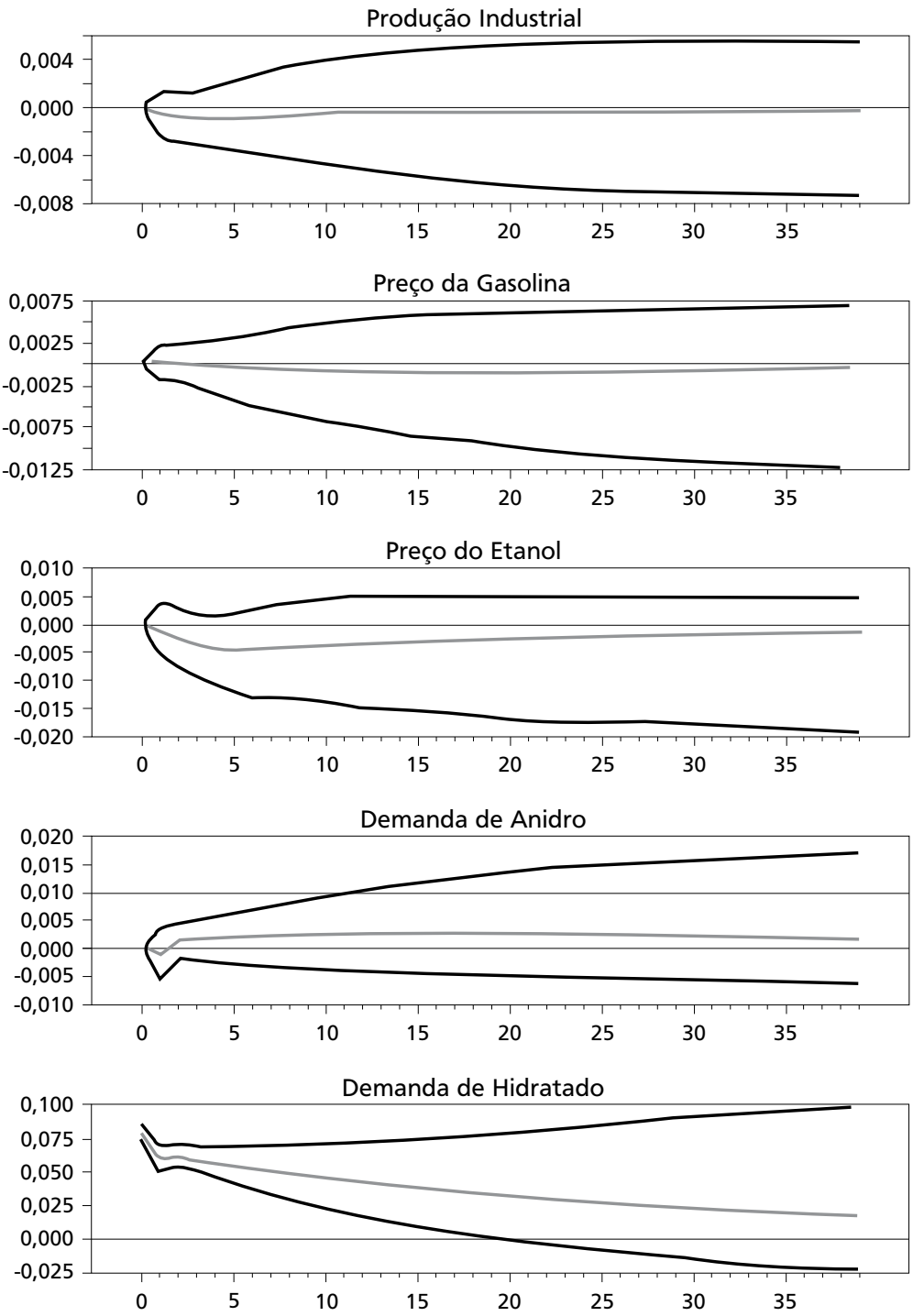

Fonte: Elaboração própria.

Realizado, então, o processo de identificação, observaram-se as estimações do SVAR através da função impulso resposta e decomposição da variância. Ou seja, mostra-se como a demanda de etanol responde a mudanças nos preços da gasolina e do etanol. Um resultado interessante é mostrado na Figura 5, na qual um choque de demanda de etanol não oferece nenhuma reação nas variáveis de análise do modelo. Esse resultado sugere 
que o aumento na demanda de etanol causado por um estímulo ao uso de biocombustíveis não causa no curto e longo prazo mudanças significativas das variáveis.

É de interesse também mostrar como as demandas de etanol anidro e hidratado reagem a mudanças de preço do etanol e da gasolina. As Figuras 6 e 7 mostram a reação da demanda de etanol anidro e hidratado quando ocorre um choque no preço da gasolina. Observa-se que, quando há um choque de preço da gasolina, a demanda de etanol anidro sofre um aumento repentino e, no entanto, vai diminuindo ao longo do tempo até se estabilizar após um ano. Esse resultado mostra que, quando o choque de gasolina é repentino, os consumidores, em um primeiro momento, preferem gasolina a etanol e, logo após um tempo, a preferência é maior pelo etanol. De fato, o mesmo choque de gasolina na Figura 7 mostra que a demanda de etanol hidratado permanece sempre variando de forma positiva, porém constante. $\mathrm{O}$ resultado sugere que o efeito complementaridade é maior do que o efeito substituição entre os combustíveis. Portanto, a troca de consumo de gasolina pelo consumo de etanol é feita apenas no longo prazo.

\section{Figura 6 - Reação da demanda de etanol anidro a um choque no preço da gasolina}

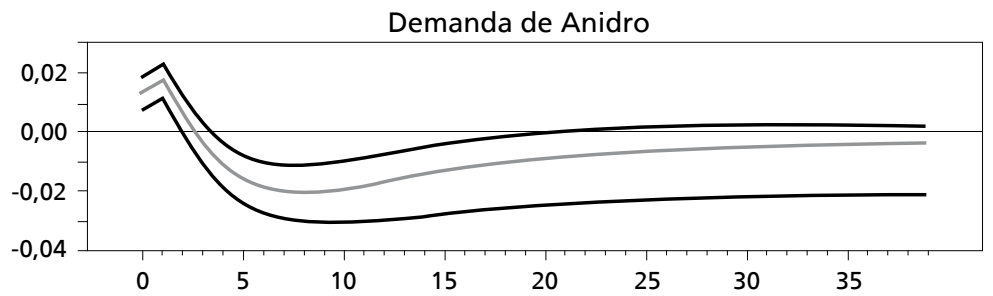

Fonte: Elaboração própria.

Figura 7- Reação da demanda de etanol hidratado a um choque no preço da gasolina

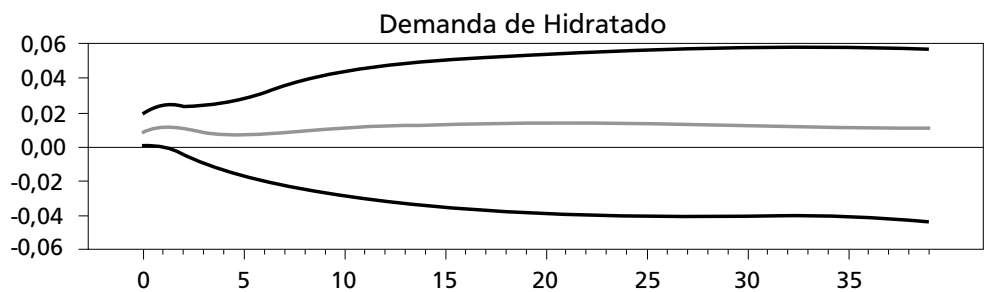

Fonte: Elaboração própria.

As Figuras 8 e 9 mostram as respostas das demandas de etanol a um choque no preço do etanol hidratado. Um choque positivo no preço do etanol causa um aumento 
na demanda de etanol anidro, sendo assim uma substituição de etanol por gasolina ao longo do tempo. No entanto, essa variação na demanda de etanol anidro é muito pequena. Já a demanda de etanol hidratado tem uma variação negativa e persistente no longo prazo, denotando, assim, a preferência do consumidor em abastecer o carro com gasolina.

Figura 8 - Reação da demanda de etanol anidro a um choque no preço do etanol

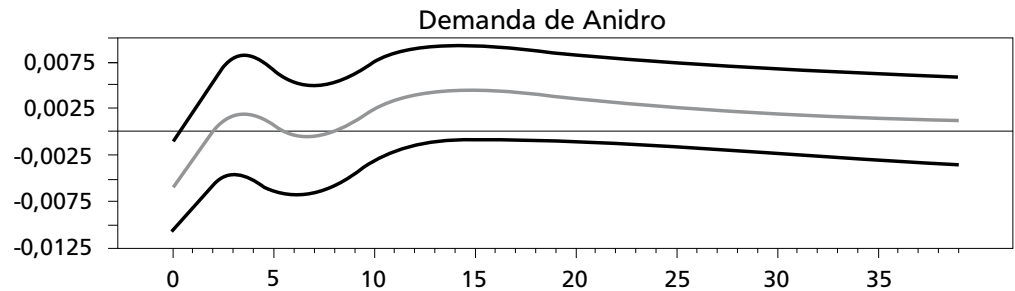

Fonte: Elaboração própria.

Figura 9 - Reação da demanda de etanol hidratado a um choque no preço do etanol

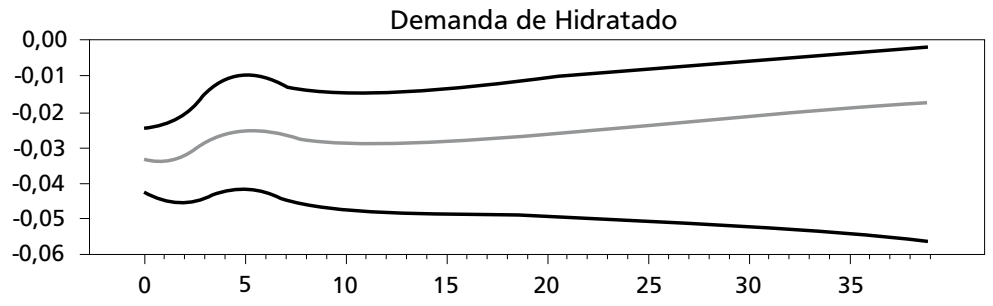

Fonte: Elaboração própria.

Para uma melhor análise observamos as respostas de um choque de um ponto percentual nos preços dos combustíveis. A Tabela 4 mostra as respostas das variáveis selecionadas quando ocorrem choques de $1 \%$ no preço da gasolina. Nota-se que a maior resposta da demanda de etanol anidro é de -0,91, e o maior valor da elasticidade-preço cruzada da demanda de etanol hidratado é 0,80 , corroborando, assim, com a análise gráfica, a qual indica que gasolina e etanol têm um maior grau de complementaridade do que substituição. A demanda de etanol anidro reduz mais, mas a demanda de etanol hidratado aumenta um pouco menos.

Analisando a resposta das demandas ao longo do tempo tem-se que o grau de complementaridade é reduzido no longo prazo e o grau de substituição aumenta, ressaltando, assim, que mais etanol hidratado é demandado no longo prazo. 
Tabela 4 - Respostas acumuladas (em valor absoluto) das variáveis selecionadas a um choque de $1 \%$ no preço da gasolina (\%)

\begin{tabular}{|c|c|c|c|c|c|c|}
\hline Variável & $\begin{array}{l}\text { Resposta } \\
\text { Máxima }\end{array}$ & $\begin{array}{c}\text { Resposta } \\
\text { Acumulada } \\
\text { Máxima }\end{array}$ & $\begin{array}{c}\text { Resposta } \\
\text { Acumulada até } \\
\text { o } 10^{\circ} \text { período }\end{array}$ & $\begin{array}{c}\text { Resposta } \\
\text { Acumulada até } \\
\text { o } 20^{\circ} \text { período }\end{array}$ & $\begin{array}{c}\text { Resposta } \\
\text { Acumulada até } \\
\text { o } 30^{\circ} \text { período }\end{array}$ & $\begin{array}{c}\text { Resposta } \\
\text { Acumulada até } \\
\text { o } 40^{\circ} \text { período }\end{array}$ \\
\hline $\begin{array}{l}\text { Demanda } \\
\text { de Etanol } \\
\text { Anidro }\end{array}$ & $-0,91$ & $-6,19$ & $-3,28$ & $-6,19$ & $-2,73$ & $-1,69$ \\
\hline $\begin{array}{l}\text { Demanda } \\
\text { de Etanol } \\
\text { Hidratado }\end{array}$ & 0,80 & 7,95 & 3,72 & 5,83 & 7,71 & 7,95 \\
\hline
\end{tabular}

Fonte: Elaboração própria.

A Tabela 5 mostra a resposta das demandas de etanol anidro e hidratado quando ocorre um aumento de um ponto percentual no preço de etanol. Observa-se que, num aumento de $1 \%$ no preço do etanol, a maior resposta da demanda de etanol anidro encontra-se no primeiro momento do choque. Já a maior resposta da demanda de etanol hidratado ocorre dois meses após o choque no preço, o que consiste, assim, em uma rápida substituição dos combustíveis no primeiro momento após o choque.

Considerando a resposta ao longo do tempo, observa-se que o efeito substituição é reduzido no longo prazo, chegando a 0,50\%. Entretanto, a demanda de etanol hidratado tem uma elasticidade bastante acentuada. O efeito geral no longo prazo é que a demanda de etanol total é reduzida, ressaltando, assim, o efeito substituição maior que o efeito complementaridade.

Tabela 5 - Respostas acumuladas (em valor absoluto) das variáveis selecionadas a um choque de $1 \%$ no preço de etanol (\%)

\begin{tabular}{|c|c|c|c|c|c|c|}
\hline Variável & $\begin{array}{l}\text { Resposta } \\
\text { Máxima }\end{array}$ & $\begin{array}{c}\text { Resposta } \\
\text { Acumulada } \\
\text { Máxima }\end{array}$ & $\begin{array}{c}\text { Resposta } \\
\text { Acumulada até } \\
\text { o } 10^{\circ} \text { período }\end{array}$ & $\begin{array}{c}\text { Resposta } \\
\text { Acumulada até } \\
\text { o } 20^{\circ} \text { período }\end{array}$ & $\begin{array}{c}\text { Resposta } \\
\text { Acumulada até } \\
\text { o } 30^{\circ} \text { período }\end{array}$ & $\begin{array}{c}\text { Resposta } \\
\text { Acumulada até } \\
\text { o } 40^{\circ} \text { período }\end{array}$ \\
\hline $\begin{array}{l}\text { Demanda } \\
\text { de Etanol } \\
\text { Anidro }\end{array}$ & $-0,16$ & 1,14 & $-0,16$ & 1,14 & 0,91 & 0,50 \\
\hline $\begin{array}{l}\text { Demanda } \\
\text { de Etanol } \\
\text { Hidratado }\end{array}$ & $-0,95$ & $-8,11$ & $-8,11$ & $-7,8$ & $-6,84$ & $-5,71$ \\
\hline
\end{tabular}

Fonte: Elaboração própria.

É pertinente também analisar a contribuição de cada preço na variação das demandas de etanol anidro e hidratado. Essa contribuição pode ser vista através da decomposição da variância que mostra o quanto cada variável endógena ao modelo contribui para o erro de previsão da variável de interesse. Esse resultado é visto na Tabela 
6. A Tabela mostra que a variação da demanda de etanol anidro no curto prazo depende mais dela mesma do que das outras (estrutura autorregressiva). À medida que o tempo avança para o décimo mês, a contribuição do preço da gasolina passa a ser de $31 \%$ da variação da demanda. No quadragésimo mês, a contribuição do preço da gasolina na variância da demanda de etanol anidro é de $39 \%$. Com relação à demanda de etanol hidratado, a importância da variação se deve a ela mesma ao longo do tempo. No quadragésimo mês, o preço do etanol contribui com $17 \%$ da variância da demanda. Esse resultado indica que o comportamento da demanda total de etanol tem uma contribuição significativa da variação do preço da gasolina. O preço do etanol não possui uma importância significativa. É sugerido que o preço da gasolina possui mais importância na decisão do consumidor na escolha do combustível.

\section{Tabela 6 - Decomposição da variância das demandas de etanol anidro e hidratado (\%)}

\begin{tabular}{lcccccc}
\hline Variável & Mês & $\begin{array}{c}\text { Nível de } \\
\text { Atividade }\end{array}$ & $\begin{array}{c}\text { Preço } \\
\text { Gasolina }\end{array}$ & $\begin{array}{c}\text { Preço } \\
\text { Etanol }\end{array}$ & $\begin{array}{c}\text { Demanda } \\
\text { Anidro }\end{array}$ & $\begin{array}{c}\text { Demanda } \\
\text { Hidratado }\end{array}$ \\
\hline & 1 & 0,439 & 6,324 & 1,325 & 91,912 & 0 \\
Demanda de etanol anidro & 10 & 1,958 & 31,441 & 0,672 & 65,52 & 0,409 \\
& 20 & 10,137 & 40,249 & 2,034 & 46,614 & 0,966 \\
& 30 & 14,609 & 39,291 & 2,717 & 42,149 & 1,235 \\
& 40 & 14,819 & 39,247 & 2,746 & 41,935 & 1,254 \\
\hline \multirow{2}{*}{ Demanda de etanol hidratado } & 1 & 0,202 & 1,059 & 14,218 & 2,558 & 81,963 \\
& 10 & 0,523 & 1,797 & 17,36 & 3,035 & 77,285 \\
& 20 & 1,611 & 1,765 & 18,051 & 2,767 & 75,806 \\
& 30 & 3,318 & 1,627 & 17,715 & 2,693 & 74,647 \\
\hline
\end{tabular}

Fonte: Elaboração própria.

Com relação às variáveis que indicam a introdução dos veículos flex no Brasil, a crise de 2009 e a intervenção da mistura, podem-se observar pela estimação do VAR os coeficientes do sistema de equações. A estimação completa pode ser vista no anexo deste trabalho.

Observa-se que nenhuma dessas variáveis influenciou o preço da gasolina e o do etanol. Esse resultado indica para a gasolina uma proteção do governo no comportamento do preço do combustível fóssil, como já explicado no artigo de Melo e Sampaio (2012). Para o etanol, é possível sugerir que sua oferta estava sendo suprida de acordo com o aumento da demanda e, assim, não houve impactos no preço do etanol com o advento dos veículos flex.

Com relação à crise de 2009, o preço do etanol teve uma influência do período, com um coeficiente de $0,047 \%$ de efeito no preço de etanol. Esse resultado confirma o 
que foi apresentado por Viegas (2011), ou seja, que o preço do etanol subiu após a crise devido a uma carência de investimentos em usinas que gerou uma necessidade de importação de etanol para suprir a demanda interna. Todas essas variáveis também não interferiram na demanda total de etanol, exceto a introdução de veículos flex, que causou um impacto positivo na demanda de etanol através da demanda de etanol anidro.

Como implicação no mercado de etanol, observa-se por meio do modelo que o consumidor toma como base a escolha do combustível observando o preço da gasolina. Além disso, os resultados sugerem que a demanda de etanol é bastante influenciada pelo preço da gasolina. Mesmo com o preço da gasolina protegido, pode ser um fator positivo para o setor; o produtor se beneficia com o aumento do preço da gasolina no longo prazo, pois a demanda de etanol hidratado aumenta. No entanto, o controle do governo no preço da gasolina via imposição da mistura é uma maneira de beneficiar o setor sucroalcooleiro no sentido de aumentar a produção via aumento do percentual da mistura do etanol na gasolina.

Para efeitos de robustez do modelo, foi testado o mesmo método de estimação, porém, trocando a ordem de entrada das variáveis, ocasião em que foi possível notar que os resultados não foram modificados com essas mudanças. Além disso, testou-se o modelo com uma maior memória autorregressiva das variáveis (3 e 4 defasagens), e observou-se também que os resultados não sofreram significantes.

\section{CONCLUSÕES}

Este artigo visou a analisar os efeitos substituição e complementaridade entre os combustíveis etanol e gasolina. A finalidade é tornar mais claro como a demanda de etanol reage à mudança de preço dos combustíveis. A revisão de literatura ressaltou que a maioria dos trabalhos analisou o efeito substituição entre os combustíveis; porém, o fato de gasolina e etanol serem bens complementares foi menos abordado pela literatura. Este trabalho objetivou, também, explicar a complexa relação entre esses mercados, que foi reacendida pelo advento dos veículos flex em 2003. Para desenvolver tal análise, foi proposto o método de modelo de vetores autorregressivos estrutural SVAR, no qual todas as variáveis de interesse são endógenas e, com isso, foi possível analisar como cada variável causa e é causada uma pela outra.

Como resultado observou-se que um choque na demanda de etanol hidratado, principalmente com o advento dos veículos flex, não causou impactos significativos na dinâmica dos dois mercados. De acordo com os resultados do modelo, os consumidores aumentaram a demanda por etanol, devido a um aumento do preço da gasolina. Um choque no preço da gasolina tem um efeito complementaridade maior do que o 
efeito substituição. No longo prazo, no entanto, os consumidores substituem mais etanol com relação à gasolina. Um aumento no preço do etanol, por sua vez, não gera impactos significativos na demanda de etanol anidro, mas a demanda de etanol hidratado se reduz ao longo do tempo.

Esse resultado retrata o que ocorre com o setor sucroalcooleiro nos últimos anos. Embora tenha se afirmado que a gasolina era o substituto do etanol, a demanda desse biocombustível não estava sendo suprida, devido à falta de investimentos em novas usinas por conta da crise. Com isso, o preço do etanol começou a aumentar e, assim, os consumidores preferiram abastecer com gasolina misturada com etanol. Para assegurar o sucesso do etanol como substituto à gasolina, deve haver um conjunto de incentivos que precisam ser bem aproveitados por toda a cadeia do biocombustível. Dentre os incentivos destaca-se a institucionalização de regras claras e duradouras que favoreçam a estabilidade, a equalização e a redução de impostos e linhas de financiamento em condições especiais para ampliação da capacidade produtiva (Viegas, 2011). Esses incentivos serão mais bem aproveitados caso os empresários exerçam a função de imobilizar capital, assumir riscos e contribuir para o crescimento do mercado. Isso, portanto, garante a competitividade entre esses dois mercados.

Um dos fatores que o produtor do setor sucroalcooleiro defende é a não intervenção do governo no preço da gasolina. No entanto, esse fator pode não beneficiar o setor para um planejamento ou investimento futuro, tendo em vista que o preço do combustível fóssil é atrelado a variações do preço do barril, que demonstra grande volatilidade, gerando uma estabilidade nos setores. Entretanto, essa análise não é oriunda do modelo, servindo, assim, como base para estudos futuros.

Nota-se que, além do etanol, o produtor do setor sucroalcooleiro tem outro produto que advém da mesma matéria-prima do etanol - o açúcar. O produtor de etanol pode arbitrar entre produzir açúcar ou produzir etanol de acordo com os preços relativos dos produtos. Dessa forma, é necessário que se faça um estudo que relacione o mercado de açúcar na dinâmica do setor sucroalcooleiro e no mercado de gasolina.

\section{REFERÊNCIAS}

ALVES, D. C. O.; BUENO, R. L. S. Short-run, long-run and cross elasticities of gasoline demand in Brazil. Energy Economics, v. 25, p. 191-199, 2003.

AGÊNCIA NACIONAL DE PETRÓLEO (ANP). Série histórica do levantamento de preços e de margens de comercialização de combustíveis. [on-line] Defesa da Concorrência e Preços, Preços. Disponível em: <http://www.anp.gov.br/?pg=66510\&m=\&t1=\&t2=\&t3=\&t4=\&ar= \&ps $=\&$ cachebust $=1378244159487>$. Acesso em 3 set. 2014. 
AZEVEDO, B. S. Análise das elasticidades preço e renda da demanda por combustíveis no Brasil e desagregadas por regiões geográficas. Dissertação de Mestrado Profissionalizante, Programa de Pós-Graduação em Economia, Faculdades Ibmec, Rio de Janeiro, 2007.

BALCOMBE, K.; RAPSOMANIKIS, G. Bayesian estimation and selection of nonlinear vector correction models: the case of the sugar-ethanol-oil nexus in Brazil. American Journal of Agricultural Economics, v. 90, n. 3, p. 658-668, ago. 2008.

BOFF, H. P. Modeling the Brazilian ethanol market: how flex-fuel vehicles are shaping the long run equilibrium. China-USA Business Review, v. 10, n. 4, p. 245-264, 2011.

BURNQUIST, H. L.; BACCHI, M. R. P. A demanda por gasolina no Brasil: uma análise utilizando técnicas de co-integração. In: Congresso Brasileiro de Economia e Sociologia Rural, 40, Passo Fundo, RS, 2002.

CABRINI, M. F.; MARJOTTA-MAISTRO, M. C. Mercado internacional de álcool: os recentes programas de uso do produto como combustível. Agroanalysis, p. 36-36, 07 mar. 2007.

COSTA, C. C.; BURNQUIST, H. L.; GUILHOTO, J. J. M. Impacto de alterações nas exportações de açúcar e álcool nas regiões Centro-Sul e Norte-Nordeste sobre a economia do Brasil. Revista de Economia e Sociologia Rural, v. 44, p. 611-629, 2006.

DATAGRO. Disponível em <www.datagro.com.br>. Acesso em: mar. 2012.

DU, X.; CARRIQUIRY, M. A. Flex-fuel vehicle adoption and dynamics of ethanol price: lessons from Brazil and implications for the United States. In: Agricultural \& Applied Economics Association's 2011 AAEA \& NAREA Joint Annual Meeting, Pittsburgh, Pennsylvania, US, July 24-26, 2011.

ENDERS, W. Applied econometric time series. Hoboken, US: John Wiley \& Sons, 2001.

FERREIRA, A. L.; PRADO, F. P. A.; SILVEIRA, J. J. Flex cars and the alcohol price. Energy Economics, v. 31, p. 382-394, 2009.

FIGUEIRA, S. R.; BURNQUIST, H. L. Programas para álcool combustível nos Estados Unidos e possibilidades de exportação do Brasil. Agricultura São Paulo, São Paulo, v. 53, n. 2, p. 5-18, jul./dez. 2006.

GIESECKE, J. A.; HORRIDGE J. M.; SCARAMUCCI, J. A. The downside of domestic substitution of oil and biofuels: will Brazil catch the Dutch disease? Centre of Policy Studies and the Impact Project, General Paper, n. G-169, Dec. 2007.

GOLDEMBERG, J.; LUCON, O. Energia e meio ambiente no Brasil. Revista Estudos Avançados, Dossiê Energia, n. 59, 2006.

GOLDEMBERG, J.; COELHO, S. T.; LUCON, O. How adequate policies can push renewables. Energy Policy, n. 32, p. 1141-1146, 2004a.

GOLDEMBERG, J.; COELHO, S. T.; NASTARI, P. M.; LUCOND, O. Ethanol learning curve the Brazilian experience. Biomass and Bioenergy, n. 26, p. 301-304, $2004 \mathrm{~b}$.

GOMEZ, J. M. A. Fuels demand by light vehicles and motorcycles in Brazil. In: IAEE's Rio 2010 International Conference, Rio de Janeiro, RJ, 2010. Disponível em: <www.ab3e.org.br/ rio2010>. Acesso em mar. 2012.

HIRA, A.; OLIVEIRA, L. G. No substitute for oil? How Brazil developed its ethanol industry. Energy Policy, n. 37, p. 2450-2456, 2009. 
IGNACIUK, A.; VOHRINGER, F.; RUIJS, A.; VAN IERLAND, E. C. Competition between biomass and food production in the presence of energy policies: a partial equilibrium analysis. Energy Policy, p. 34, p. 1127-1138, 2006.

IOOTTY, M.; PINTO JR, H.; EBELING, F. Automotive fuel consumption in Brazil: Applying static and dynamic systems of demand equations. Energy Policy, p. 37, p. 5326-5333, 2009.

KAMIMURA, A.; SAUER, I. L. The effect of flex fuel vehicles in the Brazilian light road transportation. Energy Policy, n. 36, p. 1574-1576, 2008.

LOSEKANN, L.; CASTRO, G. R. Automóveis flex fuel: entendendo a escolha de combustível. Infopetro, Etanol, 21 mar. 2011. Disponível em: <http://infopetro.wordpress. com/2011/03/21/automoveis-flexfuel-entendendo-a-escolha-de-combustivel/>. Acesso em: set. 2011 .

MARJOTTA-MAISTRO, M. C. Ajustes no mercado de álcool e gasolina no processo de desregulamentação. Tese de Doutorado, Escola Superior de Agricultura Luiz de Queiroz, Universidade de São Paulo, Piracicaba, 2002.

MORAES, M. A. F. D. Desregulamentação do setor sucroalcooleiro do Brasil. São Paulo: Caminho Editorial, 2000.

MOREIRA, J. R.; GOLDEMBERG, J. The alcohol program. Energy Policy, n. 27, p. 229-245, 1999.

NAPPO, M. A. Demanda por gasolina no Brasil: Uma avaliação de suas elasticidades após a introdução dos carros bicombustível. Dissertação de Mestrado, Pós-Graduação em Finanças e Economia Industrial, Escola de Economia de São Paulo, Fundação Getúlio Vargas, São Paulo, 2007.

RENEWABLE FUELS ASSOCIATION (RFA). Battling for the barrel: 2013 Ethanol industry outlook. RFA, 2013. Disponível em: <http://ethanolrfa.org/page/-/PDFs/RFA\%202013\%20 Ethanol\%20Industry\%20Outlook.pdf?nocdn=1>. Acesso em: jun. 2014.

SERRA, T.; ZILBERMAN, D.; GIL, J. Price volatility in ethanol markets. European Review of Agricultural Economics, v. 38, n. 2, p. 259-280, 2011.

SHIKIDA, P. F. A.; BACHA, C. J. C. Uma análise econométrica preliminar das ofertas de açúcar e álcool paranaenses. Revista de Economia Agrícola, São Paulo, v. 54, n. 1, p. 21-32, jan./jun. 2007.

SCHÜNEMANN, L. A demanda de gasolina automotiva no Brasil: O impacto nas elasticidades de curto e longo prazo da expansão do GNV e dos carros flex. Dissertação de Mestrado Profissionalizante, Faculdade de Economia e Finanças, IBMEC, Rio de Janeiro, RJ, 2007.

SMEETS, E.; JUNGINGER, M.; FAAIJ, A.; WALTER, A. ET AL. The sustainability of Brazilian ethanol. An assessment of the possibilities of certified production. Biomass and Bioenergy, n. 32, p. 781-813, 2008.

TOKGOZ, S.; ELOBEID, A. An analysis of the link between ethanol, energy, and crop markets. Working Paper, Iowa State University, n. 06-WP 435, 2006.

UNIÃO DA INDÚSTRIA DA CANA-DE-AÇÚCAR (ÚNICA). UNICADATA. [on-line] Disponível em: <http://www.unicadata.com.br>. Acesso em 3 set. 2014. 
VENDENOV, D.; DUFFIELD, J. A.; WETZSTEIN, M. E. Entry of alternative fuels in a volatile U.S. gasoline market. In: AAEA Annual Meetings, Selected Paper n. 134421, Providence, RI, jul. 2005.

VIEGAS, T. A solução para a crise do etanol: incentivos, subsídios, regulação ou defesa da concorrência? Infopetro, Etanol, 20 jun. 2011. Disponível em: <http://infopetro.wordpress. com/2011/06/20/a-solucao-para-a-crise-do-etanol-incentivos-subsidios-regulacao-ou-defesa-da-concorrencia/>. Acesso em: set. 2011.

VILELA, T. Modelos de demanda por combustível no Brasil. Infopetro, Etanol, 14 jun. 2010. Disponível em: <http://infopetro.wordpress.com/2010/06/14/modelos-de-demanda-por-combustivel-no-brasil/>. Acesso em: set. 2011. 


\section{Apêndice}

\section{VETORES AUTORREGRESSIVOS ESTRUTURAL (SVAR)}

Para a análise da repercussão de choques sobre as demandas de etanol é considerado um modelo Vetorial Autorregressivo Estrutural (SVAR) da seguinte forma:

$$
y_{t}^{\prime} A_{0}=\sum_{l=1}^{p} y_{t-1}^{\prime} A_{l}+\varepsilon_{t}^{\prime} \text { para } 1 \leq t \leq T
$$

Onde $y_{\mathrm{t}}$ é um vetor coluna $n \times 1$ das variáveis endógenas do modelo; $A_{0}$ é uma matriz $n \times n$ dos parâmetros das variáveis contemporâneas; $A_{1}$ é uma matriz $n x n$ dos parâmetros das variáveis defasadas, para $1 \leq l \leq p$; $\varepsilon_{t}$ é um vetor coluna $n \times 1$ dos distúrbios estruturais; " $p$ " é a ordem de defasagem; e " $T$ " é o tamanho da amostra. Definindo,

$$
z_{t}^{\prime}=\left[y_{t-1}^{\prime} \ldots y_{t-p}^{\prime}\right]
$$

$\mathrm{e}$

$$
F^{\prime}=\left[A_{1} \ldots A_{p}\right]
$$

Onde $z_{\mathrm{t}}$ é uma matriz $1 x k$ e $F \notin$ é uma matriz $n x k$, com $k=n p$, e usando $z_{\mathrm{t}} z \Phi_{\mathrm{t}} \mathrm{e}$ $F \Phi$, pode-se reescrever o modelo descrito em (3) de forma mais simplificada como:

$$
y_{t}^{\prime} A_{0}=z_{t}^{\prime} F^{\prime}+\varepsilon_{t}^{\prime}
$$

Porém, sabe-se que o modelo na sua versão estrutural não é determinado, então estima-se o modelo em sua forma reduzida ou padrão, obtido pela pós-multiplicação do sistema (4) pela inversa da matriz $A_{0}, A^{-1}$ :

$$
y_{t}^{\prime}=y_{t-1}^{\prime} B+u_{t}^{\prime}
$$


Onde $B=F A^{-1} ; u_{\mathrm{t}}^{\prime}=\varepsilon_{\mathrm{t}}^{\prime} A^{-1}$ e $E\left[u_{\mathrm{t}}^{\prime} u_{\mathrm{t}}\right]=\Omega=(A A)^{-1}$ é a matriz de variância-covariância dos resíduos na forma reduzida.

A estratégia empírica envolve, portanto, estimar o modelo na forma reduzida e depois recuperar os parâmetros da forma estrutural. Tipicamente, a literatura que investiga os efeitos de choques sobre as variáveis macroeconômicas, dentre outros, segue Sims (1980) e impõe um esquema de identificação recursivo através da imposição de restrições na matriz de efeitos contemporâneos, $A_{0}$. Um exemplo de esquema de identificação que estabelece restrições nos parâmetros contemporâneos é a decomposição de Cholesky, que é comumente utilizada em estudos como o realizado aqui. A decomposição de Cholesky impõe uma estrutura recursiva para a matriz $A$, assumindo que a matriz é triangular inferior ou superior, o que significa dizer que no caso da matriz ser triangular inferior, conforme for estabelecida a ordenação das variáveis de grande relevância para as estruturas recursivas, é imposta a condição de que a primeira variável ordenada não seja afetada contemporaneamente por choques nas demais variáveis que a seguem, mas choques na primeira variável influenciam as demais. Em sequência, a segunda variável influencia as que a seguem, mas não sofre influência dessas variáveis, e assim pode-se generalizar para as demais. 


\section{Anexo}

Tabela - Estimação do VAR

\begin{tabular}{l|c|c|c|c}
\hline \multicolumn{5}{c}{ Equação 1 - Variável Dependente: Produção Industrial } \\
\hline \multicolumn{1}{c|}{ Variáveis Explicativas } & Coeficientes & Desvio Padrão & t-student & P-valor \\
\hline Produto Industrial\{1\} & 1,055552 & 0,097704 & 10,80361 & 0,00000 \\
\hline Produto Industrial\{2\} & $-0,20747$ & 0,099222 & $-2,09093$ & 0,03907 \\
\hline Preço da Gasolina\{1\} & $-0,04642$ & 0,119505 & $-0,38843$ & 0,698524 \\
\hline Preço da Gasolina\{2\} & 0,196335 & 0,126103 & 1,55695 & 0,122643 \\
\hline Preço do Etanol\{1\} & $-0,01269$ & 0,051168 & $-0,24795$ & 0,804684 \\
\hline Preço do Etanol \{2\} & $-0,05671$ & 0,050828 & $-1,11582$ & 0,267175 \\
\hline Demanda de E. Anidro\{1\} & $-0,00769$ & 0,039545 & $-0,19439$ & 0,846262 \\
\hline Demanda de E. Anidro\{2\} & $-0,01193$ & 0,042404 & $-0,28127$ & 0,779086 \\
\hline Demanda de E. Hidratado $\{1\}$ & $-0,00741$ & 0,025004 & $-0,29624$ & 0,767661 \\
\hline Demanda de E. Hidratado $\{2\}$ & 0,002744 & 0,024362 & 0,11263 & 0,910548 \\
\hline Constante & 0,379324 & 0,502057 & 0,75554 & 0,451702 \\
\hline FLEX & 0,002478 & 0,012805 & 0,19349 & 0,846969 \\
\hline MIST & 0,001857 & 0,007778 & 0,23871 & 0,811822 \\
\hline CRISE & 0,022472 & 0,010077 & 2,23015 & 0,027973 \\
\hline
\end{tabular}

Equação 2 - Variável Dependente: Preço da Gasolina

\begin{tabular}{l|c|c|c|c}
\hline \multicolumn{1}{c|}{ Variáveis Explicativas } & Coeficientes & Desvio Padrão & t-student & P-valor \\
\hline Produto Industrial $\{1\}$ & 0,161391 & 0,105546 & 1,52911 & 0,129395 \\
\hline Produto Industrial\{2\} & $-0,03963$ & 0,107186 & $-0,36977$ & 0,712335 \\
\hline Preço da Gasolina $\{1\}$ & 1,175432 & 0,129097 & 9,10501 & 0,000000 \\
\hline Preço da Gasolina\{2\} & $-0,27394$ & 0,136224 & $-2,01098$ & 0,047019 \\
\hline Preço do Etanol $\{1\}$ & 0,054248 & 0,055275 & 0,98143 & 0,328751 \\
\hline Preço do Etanol $\{2\}$ & $-0,06366$ & 0,054908 & $-1,15933$ & 0,249084 \\
\hline Demanda de E. Anidro\{1\} & $-0,03179$ & 0,042719 & $-0,74406$ & 0,458583 \\
\hline Demanda de E. Anidro\{2\} & 0,031879 & 0,045808 & 0,69593 & 0,488089 \\
\hline Demanda de E. Hidratado $\{1\}$ & 0,003376 & 0,027011 & 0,12497 & 0,900798 \\
\hline Demanda de E. Hidratado\{2\} & $-0,00309$ & 0,026317 & $-0,11753$ & 0,90668 \\
\hline Constante & 0,25224 & 0,542354 & 0,46508 & 0,642883 \\
\hline FLEX & 0,00584 & 0,013833 & 0,42218 & 0,673798 \\
\hline MIST & $-0,00743$ & 0,008403 & $-0,8837$ & 0,378978 \\
\hline CRISE & $-0,0024$ & 0,010885 & $-0,22044$ & 0,82598 \\
\hline
\end{tabular}

Equação 3 - Variável Dependente: Preço do Etanol

\begin{tabular}{l|c|c|c|c}
\hline \multicolumn{1}{c|}{ Variáveis Explicativas } & Coeficientes & Desvio Padrão & t-student & P-valor \\
\hline Produto Industrial $\{1\}$ & 0,253798 & 0,205748 & 1,23354 & 0,220266 \\
\hline Produto Industrial $\{2\}$ & $-0,30221$ & 0,208946 & $-1,44634$ & 0,151208 \\
\hline Preço da Gasolina $\{1\}$ & 0,270804 & 0,251659 & 1,07608 & 0,284482 \\
\hline Preço da Gasolina $\{2\}$ & 0,205064 & 0,265552 & 0,77222 & 0,441806 \\
\hline Preço do Etanol $\{1\}$ & 1,238067 & 0,107752 & 11,49002 & 0 \\
\hline Preço do Etanol $\{2\}$ & $-0,57714$ & 0,107036 & $-5,39203$ & $4,7 \mathrm{E}-07$ \\
\hline Demanda de E. Anidro $\{1\}$ & $-0,12087$ & 0,083276 & $-1,45148$ & 0,149775 \\
\hline Demanda de E. Anidro $\{2\}$ & 0,114738 & 0,089296 & 1,28492 & 0,201789 \\
\hline
\end{tabular}




\begin{tabular}{l|c|c|c|c}
\hline Demanda de E. Hidratado $\{1\}$ & $-0,00836$ & 0,052654 & $-0,1588$ & 0,874147 \\
\hline Demanda de E. Hidratado $\{2\}$ & $-0,01096$ & 0,051302 & $-0,21358$ & 0,831309 \\
\hline Constante & $-0,62279$ & 1,057251 & $-0,58906$ & 0,557149 \\
\hline FLEX & $-0,0353$ & 0,026966 & $-1,30898$ & 0,19354 \\
\hline MIST & $-0,00854$ & 0,01638 & $-0,52154$ & 0,603145 \\
\hline CRISE & 0,047075 & 0,02122 & 2,21847 & 0,028784 \\
\hline
\end{tabular}

Equação 4 - Variável Dependente: Produção de Etanol Anidro

\begin{tabular}{l|c|c|c|c}
\hline \multicolumn{1}{c|}{ Variáveis Explicativas } & Coeficientes & Desvio Padrão & t-student & P-valor \\
\hline Produto Industrial $\{1\}$ & $-0,03017$ & 0,245595 & $-0,12286$ & 0,902466 \\
\hline Produto Industrial $\{2\}$ & 0,135423 & 0,249412 & 0,54297 & 0,588358 \\
\hline Preço da Gasolina $\{1\}$ & 0,466324 & 0,300397 & 1,55236 & 0,123736 \\
\hline Preço da Gasolina $\{2\}$ & $-0,9514$ & 0,316981 & $-3,00145$ & 0,003393 \\
\hline Preço do Etanol\{1\} & $-0,0029$ & 0,12862 & $-0,02254$ & 0,982061 \\
\hline Preço do Etanol $\{2\}$ & 0,083949 & 0,127765 & 0,65706 & 0,512652 \\
\hline Demanda de E. Anidro\{1\} & 0,544508 & 0,099404 & 5,47774 & $3,2 \mathrm{E}-07$ \\
\hline Demanda de E. Anidro\{2\} & 0,227447 & 0,10659 & 2,13385 & 0,035301 \\
\hline Demanda de E. Hidratado $\{1\}$ & $-0,01358$ & 0,062851 & $-0,21606$ & 0,82938 \\
\hline Demanda de E. Hidratado $\{2\}$ & 0,031061 & 0,061237 & 0,50723 & 0,613114 \\
\hline Constante & 5,349007 & 1,262008 & 4,23849 & $5,02 \mathrm{E}-05$ \\
\hline FLEX & 0,101347 & 0,032188 & 3,14856 & 0,002163 \\
\hline MIST & 0,007866 & 0,019552 & 0,40231 & 0,688318 \\
\hline CRISE & 0,036976 & 0,025329 & 1,45982 & 0,147474 \\
\hline
\end{tabular}

Equação 5 - Variável Dependente: Demanda de Etanol Hidratado

\begin{tabular}{l|c|c|c|c}
\hline \multicolumn{1}{c|}{ Variáveis Explicativas } & Coeficientes & Desvio Padrão & t-student & P-valor \\
\hline Produto Industrial $\{1\}$ & 0,473052 & 0,420328 & 1,12543 & 0,263099 \\
\hline Produto Industrial $\{2\}$ & $-0,03603$ & 0,426861 & $-0,08441$ & 0,932902 \\
\hline Preço da Gasolina $\{1\}$ & 0,555267 & 0,514121 & 1,08003 & 0,282726 \\
\hline Preço da Gasolina $\{2\}$ & $-0,64971$ & 0,542503 & $-1,19762$ & 0,233895 \\
\hline Preço do Etanol $\{1\}$ & $-0,25553$ & 0,220129 & $-1,1608$ & 0,248485 \\
\hline Preço do Etanol $\{2\}$ & 0,301236 & 0,218667 & 1,37761 & 0,1714 \\
\hline Demanda de E. Anidro\{1\} & $-0,06641$ & 0,170127 & $-0,39038$ & 0,697088 \\
\hline Demanda de E. Anidro\{2\} & 0,083862 & 0,182426 & 0,45971 & 0,646724 \\
\hline Demanda de E. Hidratado $\{1\}$ & 0,759005 & 0,107568 & 7,05604 & 0,000000 \\
\hline Demanda de E. Hidratado\{2\} & 0,202208 & 0,104806 & 1,92936 & 0,056521 \\
\hline Constante & $-1,3587$ & 2,159888 & $-0,62906$ & 0,530744 \\
\hline FLEX & 0,000187 & 0,05509 & 0,00339 & 0,997303 \\
\hline MIST & $-0,0034$ & 0,033463 & $-0,10151$ & 0,919352 \\
\hline CRISE & $-0,05907$ & 0,043351 & $-1,3627$ & 0,17604 \\
\hline
\end{tabular}

Nota: Variáveis em logaritmo. 